\title{
NONSUICIDAL SELF-INJURY IN A NATURALISTIC SAMPLE OF ADOLESCENTS UNDERGOING INPATIENT PSYCHIATRIC TREATMENT: PREVALENCE, GENDER DISTRIBUTION AND COMORBIDITIES
}

\author{
NICHT-SUIZIDALE SELBSTVERLETZUNGEN BEI STATIONÄREN \\ PATIENTEN DER KINDER- UND JUGENDPSYCHIATRIE: \\ PRÄVALENZ, GESCHLECHTERVERTEILUNG UND \\ KOMORBIDE PSYCHOPATHOLOGIE IN EINER \\ NATURALISTISCHEN KLINISCHEN STICHPROBE
}

\author{
Kathrin Sevecke, Astrid Bock, Lucas Fenzel, Manuela Gander \& Martin Fuchs \\ Department of Psychiatry, Psychotherapy and Psychosomatics in Childhood and Adolescence, \\ Medical University of Innsbruck, Innsbruck, Austria
}

\section{SUMMARY}

Background: A growing body of research points toward nonsuicidal self-injury (NSSI) in adolescents as an important and frequent health-related risk factor. In 2013, NSSI was proposed in section 3 of the DSM-5 as a new diagnostic entity warranting further study. In line with that goal, the present study was conducted in order to evaluate prevalence, gender distribution and comorbidities of NSSI in a sample of adolescent psychiatric inpatients.

Subjects and methods: The study included 130 adolescents (mean age 15.09 years, $S D \pm 1.47 ; 71.5 \%$ female) undergoing inpatient psychiatric treatment at a specialized facility. The factors assessed were sociodemographic data, the presence of NSSI according to the proposed DSM-5 criteria, clinical psychiatric diagnosis, the presence of suicidality and the presence of personality disorder.

Results: A large percentage, $38.5 \%$, of the sample fulfilled DSM-5 criteria for NSSI, and more than half (50.8\%) of the adolescents indicated having injured themselves at least once in the past. Patients with NSSI were predominantly young women and clustered in a spectrum of diagnostic entities including not only borderline personality disorders but also substance use disorders and affective disorders. A strong association was found between suicidality (suicidal ideation, history of suicide attempt) and NSSI.

Conclusions: In line with previous findings, NSSI among adolescent psychiatric inpatients was found to be a frequent phenomenon associated with a broad spectrum of comorbidities. Moreover, while NSSI is conceptualized as an act without suicidal intent, it commonly occurs in patient groups with suicidal ideation or with a history of suicide attempts.

Key words: NSSI - self-harm - suicidality - comorbidity adolescents

\section{Abbreviations:}

BPD - Borderline personality disorder;

NSSI - Nonsuicidal self-injury;

PD - Personality disorder;

SUD - Substance use disorder.

\section{ZUSAMMENFASSUNG}

Hintergrund: Eine steigende Zahl von Forschungsarbeiten belegt die Bedeutung von nicht-suizidalen Selbstverletzungen (NSSV) als häufigen und wichtigen gesundheitsbezogenen Risikofaktor bei Jugendlichen. 2013 wurden NSSV im DSM-5 in den Abschnitt 3 der weiter zu beforschenden Entitäten aufgenommen. Das Ziel dieser Studie war dementsprechend, Prävalenz, Geschlechterverteilung und komorbide Psychopathologie in einer Stichprobe von jugendlichen stationären Patienten zu untersuchen.

Sample und Methoden: In die Studie wurden 130 Jugendliche (mittleres Alter 15,09 Jahre, $S D \pm 1,47 ; 71,5 \%$ weiblich) eingeschlossen, die als stationäre Patienten an einer kinderund jugendpsychiatrischen Klinik aufgenommen waren. Neben soziodemographischen Daten waren die erhobenen klinischen Variablen die Prävalenz von NSSV nach den DSM-5 - Kriterien, die klinisch-psychiatrische Diagnose, das Vorliegen einer Persönlichkeitsstörung sowie das Vorliegen von Suizidalität.

Resultate: Ein hoher Prozentsatz von 38,5\% der stationären Patienten erfüllten die DSM-5-Kriterien für NSSV, mehr als die Hälfte der Jugendlichen (50,8\%) gaben an, sich in der Vergangenheit schon einmal selbst verletzt zu haben. NSSV kamen häufiger bei weiblichen Patientinnen vor, und zeigten eine signifikante Häufung in einem Spektrum von klinischen Diagnosen, welches nicht nur Borderline-Persönlichkeitsstörungen sondern auch Suchterkrankungen und affektive Störungen beinhaltete. NSSV waren hochsignifikant mit Suizidalität (Suizidgedanken, Suizidversuch in Anamnese) assoziiert.

Schlussfolgerungen: Im Einklang mit bisheriger Literatur zeigten sich NSSV in unserer Studie als ein häufiges Phänomen, welches mit einem breiten Spektrum von komorbiden Störungen assoziiert war. Obwohl NSSV per definitionem ohne suizidale Absicht ausgeführt werden, besteht eine enge Verbindung zu Suizidgedanken sowie Suizidversuchen in der Anamnese.

Schlüsselwörter: NSSV - Selbstverletzung - Suizidalität Komorbidität - Jugendliche 


\section{INTRODUCTION}

While the oldest indications of self-harming behavior can be traced back to antiquity (Favazza 1998), it was not until 2013 that a psychiatric association attempted to formulate general research criteria for this phenomenon (APA 2013). An intense scientific discourse has occurred over the past two decades, paving the way for a consistent terminology. The established consensus has been to define and classify self-harming behavior according to whether its principal intent is suicidal or nonsuicidal (NSSI) (Nock 2010). Despite remaining differences in the literature as to the weighting and assessment of various aspects of NSSI, a general definition of the phenomenon may be derived from available recommendations, research findings and classification efforts. The research criteria for NSSI specified in section 3 of DSM-5, "Emerging Measures and Models", have met with wide acceptance in the scientific community (Zetterqvist 2015). According to these criteria, NSSI may be defined as the repetitive, deliberate and planned destruction of body tissue not resulting from suicidal intent and not as part of socially sanctioned practices (e.g. body piercings, tattoos or acts associated with religious or cultural traditions). NSSI is nearly always done for the purpose of psychological relief/release, and it is frequently associated with interpersonal problems or aversive cognitions immediately preceding the self-injury. The frequency criterion ("five or more attempts within one year") stresses the repetitive character of the disorder. By definition, such selfharming behavior cannot be better explained by another disorder or disease, and it does not occur exclusively during florid episodes of psychiatric illness.

NSSI represents a substantial health threat, particularly in adolescence: whereas the point prevalence for all psychiatric disorders combined lies between 15\% and 25\% (Fuchs et al. 2013, Fuchs et al. 2016, Fuchs \& Karwautz 2017), international findings show that approximately one in five adolescents in the general population has injured himself or herself at least once (Muehlenkamp et al., 2012). In clinical samples, nearly half of all adolescents in stationary care report having harmed themselves at least once (Kaess et al. 2013). Although a relatively large number of adolescents in the general population have experimented with NSSI, only 4\%-6.7\% show repetitive, deliberate self-injuries meeting DSM-5 criteria (Zetterqvist et al. 2013, Plener et al. 2012). In clinical samples, however, self-harming adolescents meet DSM-5 criteria for NSSI far more frequently: between $30 \%$ and $61 \%$ in studies to date (Wolff et al. 2013, Kaess et al. 2013, Glenn \& Klonsky 2013).

As to gender distribution, findings in single studies and meta-analyses have been inconsistent: while some have found no indications of significant gender differences (Muehlenkamp \& Gutierrez 2004, Swanell et al. 2014), others have reported higher prevalence among females (Zetterqvist 2017, Bresin \& Schoenleber 2015, Groschwitz et al. 2015a, Brunner et al. 2007). The two cited meta-analyses (Swanell et al. 2014, Bresin \& Schoenleber 2015) included both adolescents and adults, but the age of subjects was not found to be a confounding factor in either study.

In addition to the standardization of criteria, which provides a necessary basis for further replicable research, the introduction of NSSI as an entity is important for another reason: previous editions of the DSM and the current ICD-10 (Dilling \& Freyberger 2015) include self-harming behavior only as a symptom of borderline personality disorder (BPD). Yet current data indicate that NSSI in adolescence is a symptom of BPD in only $20 \%-50 \%$ of cases, frequently in combination with depressive disorders or substance use disorders (SUD), and can even occur in a small percentage without any other psychopathology (Jacobson \& Gould 2007, Jacobson et al. 2008, Glenn \& Klonsky 2015, Nock et al. 2006, Stanford \& Jones 2009, In-Albon 2013).

Longitudinal studies on NSSI thus far have suggested that a peak frequency is reached at around the age of 15 , with a marked decline of symptoms occurring in early adulthood (Plener et al. 2015). Despite this decline and, by definition, the lack of original suicidal intent, adolescent self-harming behavior represents a significant risk factor for suicide attempts in adolescence and young adulthood as well as a risk factor for the later development of BPD. The combination of suicidal thoughts plus NSSI in adolescence appears to be the strongest predictor of later suicide attempts in young adulthood. Patients with episodes of self-harming behavior in adolescence have been shown to carry heavy psychosocial and psychological burdens later in life (Castellví et al. 2017, Grandclerc et al. 2016, Ribeiro et al. 2016, Groschwitz et al. 2015b, Scott et al. 2015, Tuisku et al. 2014, Guan et al. 2012, Wilkinson et al. 2011, Sinclair et al. 2010, Lofthouse \& Yager-Schweller 2009).

The aim of the present study was to examine the phenomenon of adolescent self-injury in a sample of psychiatric inpatients. The overall prevalence of selfharming behavior was assessed, as was the prevalence of NSSI according to DSM-5 criteria. These findings were compared with gender and psychiatric discharge diagnosis.

\section{SUBJECTS AND METHODS}

\section{Subjects}

The sample consisted of 130 adolescents (mean age: 15.09 years, SD: \pm 1.47 a; $71.5 \%$ female) undergoing inpatient psychiatric treatment at the Department of Psychiatry, Psychotherapy and Psychosomatics in Childhood and Adolescence, Medical University of Innsbruck. This specialized facility has a public service mandate for the Austrian federal state of Tyrol, and it is the only hospital in the state with inpatient services for minors with mental health problems. Written informed consent was obtained from the participants and from their parents or legal guardians. The study was approved by the 
Ethics Committee of the Medical University of Innsbruck and was performed according to the Declaration of Helsinki (1995), as revised in Edinburgh (2000).

\section{Methods}

Gender, age, principal psychiatric diagnosis and the presence of suicidality (suicidal ideation, one or more suicide attempts) were compared between patients with NSSI and patients without NSSI. Among patients with a history of self-injury, the sample was divided into two groups: those showing self-inflicted injuries generally and those fulfilling DSM-5 criteria for NSSI. For each adolescent, the assessment of whether DSM-5 NSSI criteria were fulfilled was based on thorough research from multiple information sources (medical history, physicians' letters, consultation reports, care documentation and status at admission and discharge). Furthermore, consultation with attending physicians provided information on the presence of DSM-5 research criteria, e.g. typical behavior patterns and indications of recent/fresh cuts. The gender of each patient and the electronically coded discharge diagnosis according to ICD-10 (principal diagnosis) were also recorded.

Completed SCID-II interviews were available for 109 of the 130 patients. The Structured Clinical Interview (SCID) for DSM-IV is the official instrument of the American Psychiatric Association for the determination of mental disorders via interview diagnostics. Personality disorders are assessed using the SCID-II, the German translation (SKID-II, Fydrich et al. 1997) of which was used for this study. SCID-II consists of two parts: a questionnaire that subjects fill out themselves and an interview in which answers from the questionnaires are checked for the fulfillment of specific criteria. A study on a German sample demonstrated that the SCID-II is an appropriate instrument for the purposes of child and adolescent psychiatry (Salbach-Andeae et al. 2008). The final step of data collection was to determine whether suicidal thoughts or attempted suicides had been recorded in patients' histories.

\section{Statistical Analysis}

Sample characteristics are given as frequencies, ranges, means and standard deviations. Gender, age, principal psychiatric diagnosis and the presence of suicidality (suicidal ideation, one or more suicide attempts) were compared between patients with NSSI and patients without NSSI. Group comparisons were calculated using chi-squared tests or Fisher's exact test for nominal data. Effect sizes were determined in order to evaluate the strength of mean differences. Whenever possible, the phi-coefficient was chosen as the measuring unit for all effect size calculations. A phi value between 0.1 and 0.29 was considered small, between 0.30 and 0.49 moderate and $\geq 0.5$ large (Ellis 2010). All statistical analyses were performed with SPSS (V. 24).

\section{RESULTS}

The study sample consisted of 130 adolescent inpatients between 11 and 17 years of age, with a mean age of 15.09 years (SD 1.47). Females made up 71.5\% of the subjects.

In total, 66 patients $(50.8 \%)$ were identified as having experienced at least one self-injury in the past. Analysis of multiple information sources identified 50 patients $(38.5 \%)$ as fulfilling the DSM-5 criteria for NSSI. Thus, $75 \%$ of all subjects with at least one episode of self-injury also fulfilled the DSM-5 criteria for NSSI. For further calculations, the sample was divided into an NSSI group (50 patients, 38.5\%) and a non-NSSI group (80 patients, $61.5 \%$ ).

Table 1 shows a comparison of the NSSI and nonNSSI groups with regard to demographic features (age, gender), psychiatric diagnosis, suicidality (ideation, attempt) in the past and the results of the SCID-II.

The NSSI and non-NSSI groups showed almost exactly the same mean age (15.10 years in the NSSI group vs. 15.08 years in the non-NSSI group). Whereas $88 \%$ of the NSSI group were young women, only $61 \%$ of the non-NSSI group were female, a statistically significant group difference $(\mathrm{p}=0.001, \Phi=0.29)$.

With regard to psychiatric diagnosis, NSSI was observed in the following diagnostic categories: substance use disorders (F1), affective disorders (F3), adjustment disorders (F43), eating disorders (F5), personality disorders (F6), externalizing disorders (F90, F91; hyperkinetic disorders and conduct disorders), mixed disorders of conduct and emotions (F92) and emotional disorders with onset specific to childhood (F93). Overall, the largest diagnostic groups with co-occurring NSSI were, in descending order: affective disorders (F3), adjustment disorders (F43), emotional disorders with onset specific to childhood (F93) and substance use disorders (F1).

Within diagnostic entities, group differences between patients with and without NSSI were calculated. There were diagnostic groups in which co-occurrence with NSSI was an important feature that showed statistical significance and small to moderate effect size when distinguishing between NSSI and non-NSSI. Within diagnostic groups, NSSI clusters were found for SUD ( $p=0.021, \Phi=0.21)$, affective disorders $(p=0.021$, $\Phi=0.20)$ and BPD $(p=0.021, \Phi=0.20)$. In patients with anorexia nervosa, an inverse correlation was found: within this diagnostic entity, those patients showing NSSI behavior were in the minority ( $\mathrm{p}=0.005, \Phi=0.29)$. The diagnostic groups in which NSSI and non-NSSI patients were distributed almost equally (resulting in large p-numbers and small effect sizes) were: mixed disorders of conduct and emotions, emotional disorders with onset specific to childhood, adjustment disorders and externalizing disorders. 
Table 1. Comparison between NSSI and Non-NSSI samples: sociodemographic features, psychiatric diagnosis, suicidality, SCID-II

\begin{tabular}{|c|c|c|c|c|c|}
\hline & $\begin{array}{l}\text { NSSI } \\
(\mathrm{n}=50)\end{array}$ & $\begin{array}{c}\text { Non-NSSI } \\
(\mathrm{n}=80)\end{array}$ & Statistics & $\mathrm{p}$ & Effect size* \\
\hline \multicolumn{6}{|l|}{ Sociodemographic features } \\
\hline Age $($ mean/SD) & $15.1(1.46)$ & $15.08(1.48)$ & $\mathrm{U}$ & 0.932 & $\mathrm{r}=0.01$ \\
\hline Gender $(\%$ female $)$ & $88 \%$ & $61 \%$ & $\chi^{2}$ & 0.001 & $\Phi=0.29$ \\
\hline \multicolumn{6}{|l|}{ Clinical psychiatric diagnosis (ICD-10)** } \\
\hline SUD (F1) & $22.0 \%$ & $7.50 \%$ & $\chi^{2}$ & 0.017 & $\Phi=0.21$ \\
\hline Affective disorder (F3) & $40.0 \%$ & $21.25 \%$ & $\chi^{2}$ & 0.021 & $\Phi=0.20$ \\
\hline Adjustment disorders (F43) & $26.0 \%$ & $18.75 \%$ & $\chi^{2}$ & 0.328 & $\Phi=0.09$ \\
\hline Any eating disorder (F5) & $16.0 \%$ & $27.50 \%$ & $\chi^{2}$ & 0.130 & $\Phi=0.13$ \\
\hline AN $(\mathrm{F} 50.0)$ & $2.0 \%$ & $21.25 \%$ & $\chi^{2}$ & 0.005 & $\Phi=0.29$ \\
\hline $\mathrm{BPD}(\mathrm{F} 60.3)$ & $10.0 \%$ & $1.25 \%$ & Fisher's test & 0.021 & $\Phi=0.20$ \\
\hline Mixed disorder of conduct and emotions (F92) & $20.0 \%$ & $11.25 \%$ & $\chi^{2}$ & 0.169 & $\Phi=0.12$ \\
\hline Emotional disorders with onset specific to childhood (F93) & $24.0 \%$ & $17.50 \%$ & $\chi^{2}$ & 0.367 & $\Phi=0.09$ \\
\hline Externalizing disorders (F90, F91) & $12.0 \%$ & $10.00 \%$ & $\chi^{2}$ & 0.960 & $\Phi=0.01$ \\
\hline \multicolumn{6}{|l|}{ Suicidality } \\
\hline Ideation & $96.0 \%$ & $40 \%$ & $\chi^{2}$ & $<0.001$ & $\Phi=0.56$ \\
\hline Attempt & $40.0 \%$ & $15 \%$ & $\chi^{2}$ & 0.001 & $\Phi=0.28$ \\
\hline \multicolumn{6}{|l|}{ SCID-II *** } \\
\hline & $\begin{array}{c}\text { NSSI } \\
(\mathrm{n}=43)\end{array}$ & $\begin{array}{c}\text { Non-NSSI } \\
(\mathrm{n}=66)\end{array}$ & & & \\
\hline Any PD & $48.8 \%$ & $19.7 \%$ & $\chi^{2}$ & 0.001 & $\Phi=0.31$ \\
\hline BPD & $14 \%$ & $1.5 \%$ & Fisher's test & 0.015 & $\Phi=0.25$ \\
\hline
\end{tabular}

Suicidality was the factor that showed the most conspicuous clustering of NSSI patients: patients suffering from suicidal ideation $(\mathrm{p}<0.001, \Phi=0.56)$ and patients with a history of a suicide attempt $(\mathrm{p}=0.001, \Phi=0.28)$ were significantly more likely to fulfill the DSM-5 criteria for NSSI.

As SCID-II was incomplete or missing for 21 patients, 109 patients were included in the statistical calculations based on this instrument. Of these, 31.2\% fulfilled SCID-II criteria for any PD, and $6.4 \%$ fulfilled SCID-II criteria for a BPD. The NSSI group consisted of 43 patients and the non-NSSI group of 66 patients. Compared to the non-NSSI group, patients with NSSI clustered in the "any PD" group $(\mathrm{p}=0.001, \Phi=0.31)$ as well as in the BPD group $(p=0.015, \Phi=0.25)$. The SCID-II criteria for a BPD were fulfilled in $14 \%$ of the patients in the NSSI group.

\section{DISCUSSION}

The aim of this study was to collect data on prevalence, gender distribution and comorbidities of NSSI in a naturalistic sample of inpatients in a specialized center for child and adolescent psychiatry.

More than half of the patients in our sample (50.8\%) were identified as having experienced at least one selfinjury in the past, and 38.5\% fulfilled DSM-5 criteria for NSSI. In community-based samples, a relatively large group of adolescents have been shown to be "experimenting" with self-injury, but only a small group of $4 \%$ to $7 \%$ hurt themselves repetitively and delibera- tely, thus falling within the category of NSSI (Zetterqvist et al. 2013, Plener et al. 2012). By contrast, selfinjuring adolescents in treatment samples fulfill DSM-5 criteria for NSSI to a much higher degree: previous findings point to rates of $30 \%-61 \%$ of adolescent psychiatric patients as showing NSSI (Groschwitz et al. 2015a, Fischer et al. 2014, Kaess et al. 2013, Glenn \& Klonsky 2013, Wolff et al. 2013). Our study thus confirms these extraordinarily high prevalence figures in treatment samples.

In the current study, significantly more young women were found in the NSSI group than in the nonNSSI group $(p=0.001, \Phi=0.29)$. This is in line with previous studies that have shown NSSI to be more prevalent among female adolescents in populationbased samples (Zetterquist et al 2017, Brunner et al. 2007) and in clinical samples (Groschwitz et al. 2015a). Yet it should be taken into account that our study was oversampled with young women: $71.5 \%$ of the adolescents in the naturalistic sample were female, which reflects treatment reality and is close to the rate of $65.8 \%$ female reported by Groschwitz et al. (2015b), who also found female gender to be a risk factor for NSSI. An older review article, which found six community-based studies reporting on this issue, yielded inconclusive data as to whether NSSI is more common among females than males (Jacobson \& Gould 2007). Taken together, there is evidence that in treatment settings, NSSI tends to occur more often in young women, whereas in community-based studies, no clear trend can be identified. 
With regard to psychiatric comorbidity, NSSI was found to cluster within a broad spectrum of diagnoses. The most common diagnostic groups were SUD $(p=0.021, \Phi=0.21)$, affective disorders $(p=0.021, \Phi=0.20)$ and BPD ( $\mathrm{p}=0.021, \Phi=0.20)$. Affective disorders were, at $40 \%$, the most common diagnostic entity within NSSI patients overall. This rate is very similar to a study performed with an adolescent treatment sample (Nock et al. 2006), where $41.6 \%$ of the patients suffered from NSSI and a comorbid major depressive disorder. Depression as a risk factor for NSSI was also reported by Groschwitz et al. (2015b) in a treatment sample comparable to ours. High rates of SUD in NSSI patients have been found in various studies - see Jacobson \& Gould (2007) for a review. In the present study, an inverse correlation was observed for anorexia nervosa: significantly fewer patients with this diagnosis were found to engage in NSSI, which is in line with previous findings (Ruuska et al. 2005). In patients with a clinical diagnosis of BPD, NSSI occurred significantly more frequently ( $\mathrm{p}=0.021, \Phi=0.20)$, which is to be expected as one of the criteria for a diagnosis of BPD is engagement in self-injurious behavior. In contrast to previous findings, only $14 \%$ of those engaging in NSSI in our study fulfilled the criteria for BPD as per SCIDII. This rate is lower than in previous studies, which have shown BPD in 20\%-75\% of adolescents engaging in NSSI (Andrewes et al. 2017, In-Albon et al. 2013, Nitkowski \& Petermann 2011, Nock et al. 2006). Taken together, findings to date cannot yet conclusively answer the question of the extent to which adolescents with NSSI suffer from comorbid BPD.

The diagnosis of PD in our study warrants further reflection. While seven adolescents fulfilled SCID-II criteria for BPD, six of them were clinically diagnosed with BPD, which is indicative of moderate interrateragreement $(\kappa=0.36)$. SCID-II criteria for "any PD" were fulfilled by 34 patients, but only nine of them were clinically diagnosed with "any PD". This difference is largely due to the formal diagnosis of "depressive personality disorder", which accounted for 23 SCID-II diagnoses. Depressive personality disorder is a controversial entity; the literature emphasizes that it may be best viewed as a "characterological variant in a spectrum of depressive disorders" (Kwon et al. 2000). As a consequence, adolescents with the formal SCID-II diagnosis of depressive personality disorder are, at our facility, diagnosed with an affective disorder. Removing this diagnosis, 11 patients in our sample remain with a SCID-II diagnosis of "any PD", which is not far from the nine in our study who were clinically diagnosed with "any PD". Such discrepancies between measuring instruments and clinical practice have been a topic of ongoing debate for a long time - in German literature (e.g. Sevecke et al. 2011, Salbach-Andrae et al. 2008) as well as in the international community (Westen \& Arkowitz-Westen 1998). A potential explanation for discrepancies may lie in the restraint exercised by many clinicians in diagnosing a PD in adolescents (Laurensen et al. 2013). Moreover, there is little to no scientific evidence for the construct validity and thus justified diagnosis of any PD other than BPD in adolescence (Sharp \& Fonagy 2015, Laurensen et al. 2013). Taken together, the moderate conformity $(\kappa=0.36)$ in our study, which was observed only for the entity "BPD", is a familiar phenomenon and part of the larger discussion of whether and how PDs other than BPD should be diagnosed in adolescence. A dimensional diagnostic approach, as proposed in section 3 of the DSM-5 (APA 2013), may be a step toward better consistency between psychological testing and clinical practice (Sevecke \& Fuchs 2017, Sevecke et al. 2014).

Although the clinical phenomenon and topic of this study is nonsuicidal self-injury, there is a close association between NSSI and suicidality, which is reflected in this study's findings as well as in previous data (Castellví et al. 2017, Grandclerc et al. 2016, Ribeiro et al. 2016, Lofthouse \& Yager-Schweller 2009). In our study, there was a significant clustering of NSSI patients compared to the non-NSSI group with regard to suicidal ideation, yielding a large effect size $(p<0.001$, $\Phi=0.56)$; a small to medium effect size ( $p=0.001$, $\Phi=0.28$ ) was found for a history of a suicide attempt. A recent meta-analysis of longitudinal studies demonstrated impressively that suicide attempts and suicide deaths in young adults were very strongly associated with previous "self-injurious thoughts and behaviors (SITB)" in adolescents. The authors reported a population attributable risk of previous SITB to suicide attempts of $26 \%$; in other words, $26 \%$ of all suicide attempts in young adulthood could have been prevented by adequately addressing SITB in adolescence (Castellví et al. 2017). In sum, our findings contribute to the robust body of evidence that has identified youth with NSSI as a high-risk group for further suicidality and thus a primary target for prevention strategies.

\section{Strengths and limitations}

This study is the first to specifically assess and compare NSSI, comorbid psychopathology and suicidality in a large sample of Austrian adolescent inpatients. The findings confirm established knowledge and highlight the relevance of NSSI as a clinical entity. Nevertheless, some limitations should be taken into account. Our study is based on diagnostic data from a specialized psychiatric hospital, and these data were not gathered using standardized diagnostic instruments. We thus cannot exclude that these best-estimate diagnoses represent a source of potential bias. Furthermore, DSM5 criteria for NSSI were assessed clinically and retrospectively using multiple information sources. The use of a standardized instrument could have improved the comparability of our results. Finally, female gender is overrepresented in our naturalistic sample, which could influence results on the one hand, but reflects treatment reality on the other hand. 


\section{CONCLUSIONS}

In line with previous findings, NSSI among adolescent psychiatric inpatients constituted a frequent phenomenon: nearly $40 \%$ of the adolescents in our sample fulfilled the proposed DSM-5 criteria for this entity.

In this study, as in previous scientific work, NSSI was associated with female gender and a broad spectrum of comorbidities, including not only BPD but also affective disorders, SUD and adjustment disorders.

Although NSSI is conceptualized as an act without suicidal intent, our study and previous findings show that affected patients show significant associations with suicidal ideation or a history of previous suicide attempts. They are thus a primary target group for prevention strategies.

As a consequence, juvenile patients showing NSSI are in need of accurate differential diagnosis concerning a potential underlying psychiatric disorder and are in need of close monitoring for suicidality.

\section{Acknowledgements: None.}

\section{Conflict of interest: None to declare.}

\section{Contribution of individual authors:}

Kathrin Sevecke: conception of the study, manuscript preparation;

Astrid Bock, Lucas Fenzel, Manuela Gander: acquisition and analysis of data;

Martin Fuchs: conception of the study, manuscript preparation, revisions and final approval of the manuscript.

\section{References}

1. American Psychiatric Association (APA): DSM-5. Diagnostic and statistical manual of mental disorders, 5th ed. Arlington 2013.

2. Andrewes HE, Hulbert C, Cotton SM, Betts J, Chanen AM: Relationships between the frequency and severity of nonsuicidal self-injury and suicide attempts in youth with borderline personality disorder. Early Interv Psychiatry 2017 Jul 18

3. Bresin $K$, Schoenleber M. Gender differences in the prevalence of nonsuicidal self-injury: A meta-analysis. Clin Psychol Rev 2015; 38:55-64.

4. Brunner R, Parzer P, Haffner J, Steen R, Roos J, Klett M, Resch F: Prevalence and psychological correlates of occasional and repetitive deliberate self-harm in adolescents. Arch Pediatr Adolesc Med 2007; 161:641-9.

5. Castellvi $P$, Lucas-Romero E, Miranda-Mendizábal A Parés-Badell O, Almenara J, Alonso I, Blasco MJ, Cebrià A, Gabilondo A, Gili M, Lagares C, Piqueras JA, Roca M, Rodríguez-Marín J, Rodríguez-Jimenez T, Soto-Sanz V, Alonso J: Longitudinal association between self-injurious thoughts and behaviors and suicidal behavior in adolescents and young adults: A systematic review with meta-analysis. J Affect Disord 2017; 215:37-48.

6. Dilling $H$ \& Freyberger H: Taschenführer zur ICD-10Klassifikation psychischer Störungen: nach dem Pocket Guide von J.E. Cooper. Hogrefe AG Bern, 2015
7. Ellis PD: The essential guide to effect sizes: Statistical power, meta-analysis, and the interpretation of research results. Cambridge, New York: Cambridge University Press 2010.

8. Favazza AR: The coming of age of self-mutilation. J Nerv Ment Dis 1998; 186:259-68.

9. Fischer G, Ameis N, Parzer P, Plener PL, Groschwitz R, Vonderlin E, Kölch M, Brunner R, Kaess M: The German version of the self-injurious thoughts and behaviors interview (SITBI-G): a tool to assess non-suicidal selfinjury and suicidal behavior disorder. BMC Psychiatry 2014; 14:265.

10. Fuchs M, Bösch A, Hausmann A, Steiner H: «The child is father of the man» - review of literature on epidemiology in child and adolescent psychiatry. Z Kinder Jugendpsychiatr Psychother 2013; 41:45-55.

11. Fuchs M, Kemmler G, Steiner H, Marksteiner J, Haring C, Miller C, Hausmann A, Sevecke K: Child and adolescent psychiatry patients coming of age: a retrospective longitudinal study of inpatient treatment in Tyrol. BMC Psychiatry 2016; 16:225

12. Fuchs $M \&$ Karwautz A: Epidemiologie psychischer Störungen bei Kindern und Jugendlichen. neuropsychiatrie 2017; DOI: 10.1007/s40211-017-0238-x

13. Fydrich T, Renneberg B, Schmitz B \& Wittchen HU: SKIDII. Strukturiertes Klinisches Interview für DSM-IV. Achse II: Persönlichkeitsstörungen. 1997, Göttingen: Hogrefe.

14. Glenn CR \& Klonsky ED. Nonsuicidal self-injury disorder: an empirical investigation in adolescent psychiatric patients. J Clin Child Adolesc Psychol 2013; 42:496-507.

15. Grandclerc S, De Labrouhe D, Spodenkiewicz M, Lachal J, Moro MR: Relations between Nonsuicidal Self-Injury and Suicidal Behavior in Adolescence: A Systematic Review. PLoS One. 2016; 18;11:e0153760.

16. Groschwitz RC, Kaess M, Fischer G, Ameis N, Schulze UM, Brunner R, Koelch M, Plener PL: The association of nonsuicidal self-injury and suicidal behavior according to DSM-5 in adolescent psychiatric inpatients. Psychiatry Res 2015; 228:454-61

17. Groschwitz RC, Plener PL, Kaess M, Schumacher T, Stoehr $R$, Boege I: The situation of former adolescent self-injurers as young adults: a follow-up study. BMC Psychiatry 2015; 15:160.

18. Guan K, Fox KR, Prinstein MJ: Nonsuicidal self-injury as a time-invariant predictor of adolescent suicide ideation and attempts in a diverse community sample. J Consult Clin Psychol 2012; 80:842-9.

19. In-Albon T, Ruf C, Schmid M: Proposed Diagnostic Criteria for the DSM-5 of Nonsuicidal Self-Injury in Female Adolescents: Diagnostic and Clinical Correlates. Psychiatry J 2013; 159208 .

20. Jacobson CM \& Gould M: The epidemiology and phenomenology of non-suicidal self-injurious behavior among adolescents: a critical review of the literature. Arch Suicide Res 2007; 11:129-47.

21. Jacobson CM, Muehlenkamp JJ, Miller A, Turner JB: Psychiatric impairment among adolescents engaging in different types of deliberate self-harm. J Clin Child Adolesc Psychol 2008; 37:363-375.

22. Kaess M, Parzer P, Mattern M, Plener PL, Bifulco A, Resch $F$ et al.: Adverse childhood experiences and their impact on frequency, severity, and the individual function of nonsuicidal self-injury in youth. Psychiatry Res 2013; 206:265-72.

23. Kwon JS, Kim YM, Chang CG, Park BJ, Kim L, Yoon DJ, Han WS, Lee HJ, Lyoo IK: Three-year follow-up of women 
with the sole diagnosis of depressive personality disorder: subsequent development of dysthymia and major depression. Am J Psychiatry 2000; 157:1966-72.

24. Laurenssen EMP, Hutsebaut J, Feenstra DJ, Van Busschbach JJ, Luyten P: Diagnosis of personality disorders in adolescents: a study among psychologists. Child Adolesc Psychiatry Ment Health 2013; 7:3.

25. Lofthouse N, Yager-Schweller J: Nonsuicidal self-injury and suicide risk among adolescents. Curr Opin Pediatr 2009; 21:641-5.

26. Muehlenkamp JJ, Gutierrez PM: An investigation of differences between self-injurious behavior and suicide attempts in a sample of adolescents. Suicide Life Threat Behav 2004; 34:12-23.

27. Muehlenkamp JJ, Claes L, Havertape L, Plener PL: International prevalence of adolescent non-suicidal selfinjury and deliberate self-harm. Child Adolesc Psychiatry Ment Health 2012; 6:10.

28. Nitkowski D, Petermann F: Non-suicidal self-injury and comorbid mental disorders: a review. Fortschr Neurol Psychiatr 2011; 79:9-20.

29. Nock MK, Joiner TE, Gordon KH, Lloyd-Richardson E, Prinstein MJ: Non-suicidal self-injury among adolescents. Diagnostic correlates and relation to suicide attempts. Psychiatry Res 2006; 144:65-72.

30. Nock MK: Self-injury. Annu Rev Clin Psychol 2010; 6:33963.

31. Peterson CM, Fischer $S:$ A prospective study of the influence of the UPPS model of impulsivity on the cooccurrence of bulimic symptoms and non-suicidal selfinjury. Eat Behav 2012; 13:335-41.

32. Plener PL, Kapusta ND, Koelch MG, Kaess M, Brunner R. Nicht-suizidale Selbstverletzung als eigenständige Diagnose. Implikationen des DSM-5 Vorschlages für Forschung und Klinik selbstverletzenden Verhaltens bei Jugendlichen. Z Kinder Jugendpsychiatr Psychother 2012, 40:113-120.

33. Plener PL, Schumacher TS, Munz LM, Groschwitz RC: The longitudinal course of non-suicidal self-injury and deliberate self-harm: a systematic review of the literature. Borderline Personal Disord Emot Dysregulation 2015; 2:2.

34. Ribeiro JD, Franklin JC, Fox KR, Bentley KH, Kleiman EM, Chang BP, Nock MK: Self-injurious thoughts and behaviors as risk factors for future suicide ideation, attempts, and death: a meta-analysis of longitudinal studies. Psychol Med 2016; 46:225-36.

35. Ruuska J, Kaltiala-Heino R, Rantanen P, Koivisto AM: Psychopathological distress predicts suicidal ideation and self-harm in adolescent eating disorder outpatients. Eur Child Adolesc Psychiatry 2005; 14:276-81.

36. Salbach-Andrae H, Bürger A, Klinkowski N, Lenz K, Pfeier E, Fydrich $T$, Lehmkuhl $U$ : Diagnostik von Persönlichkeitsstörungen im Jugendalter nach SKID-II. Z Kinder Jugendpsychiatr Psychother 2008; 36:117-25.

37. Scott LN, Pilkonis PA, Hipwell AE, Keenan K, Stepp SD: Non-suicidal self-injury and suicidal ideation as predictors of suicide attempts in adolescent girls: A multi-wave prospective study. Compr Psychiatry 2015; 58:1-10.

38. Sevecke K, Fuchs M: Persönlichkeitsstörungen im Jugendalter sind kein ,lebenslanges Schicksal“. Neurol Psychiater 2017; 18:1-2.

39. Sevecke K, Schmeck K, Krischer M: The dimensionalcategorical hybrid model of personality disorders in DSM-5 from an adolescent psychiatric perspective - criticism and critical outlook. Z Kinder Jugendpsychiatr Psychother 2014; 42:279-83.

40. Sevecke K, Lehkuhl G, Petermann F, Krischer M: Persönlichkeitsstörungen im Jugendalter - Wiedersprüche und Perspektiven. Kindheit und Entwicklung 2011; 20:256-264

41. Sharp C, Fonagy P. Practitioner Review: Borderline personality disorder in adolescence - recent conceptualization, intervention, and implications for clinical practice. J Child Psychol Psychiatry 2015; 56:1266-1288.

42. Sinclair JM, Hawton K, Gray A: Six year follow-up of a clinical sample of self-harm patients. J Affect Disord 2010; 121:247-52.

43. Stanford $S$ \& Jones MP: Psychological subtyping finds pathological, impulsive, and 'normal' groups among adolescents who self-harm. J Child Psychol Psychiatry 2009; 50:807-15.

44. Swannell SV, Martin GE, Page A, Hasking P, St John NJ: Prevalence of nonsuicidal self-injury in nonclinical samples: systematic review, meta-analysis and metaregression. Suicide Life Threat Behav 2014; 44:273-303.

45. Tuisku V, Kiviruusu O, Pelkonen M, Karlsson L, Strandholm T, Marttunen M: Depressed adolescents as young adultspredictors of suicide attempt and non-suicidal self-injury during an 8-year follow-up. J Affect Disord. 2014; 152154:313-9.

46. Westen D, Arkowitz-Westen L: Limitations of Axis II in Diagnosing Personality Pathology in Clinical Practice. Am J Psychiatry 1998; 155:1767-1771.

47. Wilkinson P, Kelvin R, Roberts C, Dubicka B, Goodyer I: Clinical and psychosocial predictors of suicide attempts and nonsuicidal self-injury in the Adolescent Depression Antidepressants and Psychotherapy Trial (ADAPT). Am J Psychiatry 2011; 168:495-501.

48. Wolff J, Frazier EA, Esposito-Smythers C, Burke T, Sloan E, Spirito A: Cognitive and social factors associated with NSSI and suicide attempts in psychiatrically hospitalized adolescents. J Abnorm Child Psychol 2013; 41:1005-13.

49. Zetterqvist $M$, Lundh LG, Dahlström O, Svedin CG: Prevalence and function of non-suicidal self-injury (NSSI) in a community sample of adolescents, using suggested DSM-5 criteria for a potential NSSI disorder. J Abnorm Child Psychol 2013; 41:759-73.

50. Zetterqvist M: The DSM-5 diagnosis of nonsuicidal selfinjury disorder: a review of the empirical literature. Child Adolesc Psychiatry Ment Health 2015; 9:31.

51. Zetterqvist M: Nonsuicidal Self-Injury in Adolescents: Characterization of the Disorder and the Issue of Distress and Impairment. Suicide Life Threat Behav 2017; 47:321-335.

\section{Correspondence:}

Martin Fuchs MD, PhD

Department of Psychiatry, Psychotherapy and Psychosomatics in Childhood and Adolescence,

Medical University of Innsbruck

Christoph Probst Platz, Innrain 52, 6020 Innsbruck, Austria

E-mail:martin.fuchs@tirol-kliniken.at 